\title{
ALPSKA POLITIKA IN NEVLADNE ORGANIZACIJE
}

\author{
Matej Ogrin \\ Oddelek za geografijo, Filozofska fakulteta, \\ Aškerčeva 2, SI- I000 Ljubljana \\ e-mail: matej.ogrin@siol.net \\ Poljudni članek \\ COBISS 1.05
}

\section{Izvleček}

Varstvo okolja v Alpah je eden od glavnih ciljev številnih nevladnih organizacij v alpskih državah. Tudi v Sloveniji se je v devetdesetih letih prejšnjega stoletja razvilo delovanje civilne družbe, ki je prispevalo k višji stopnji varstva okolja. Ena takih organizacij je CIPRA Slovenija, ki je kot del CIPRE International tudi soudeležena pri nastajanju in sprejemanju Pogodbe o varovanju Alp-Alpske konvencije.

Ključne besede: Alpe, varstvo okolja, Alpska konvencija, CIPRA Slovenija, nevladne organizacije

\section{ALPINE POLICY AND NON-GOVERNMENTAL ORGANISATIONS}

\begin{abstract}
Protection of the Alps is an aim of many NGOs in alpine countries. Since 1991 in Slovenia relatively strong movement of civil society has developed, which contributed to the higher level of protection of alpine environment. CIPRA Slovenia is a good example of such NGO. As a part of CIPRA International, contributes its share to promotion and implemen-tation of Alpine convention.
\end{abstract}

Key words: the Alps, protection of environment, Alpine convention, CIPRA Slovenia, NGO 


\section{UVOD}

Alpske pokrajine so s svojo pestrostjo in drugačnostjo že od nekdaj privlačile ljudi. Bodisi zaradi potrebe po preživetju bodisi (precej kasneje) zaradi potrebe po preživljanju prostega časa na drugačen način, kot ga poznamo ljudje, ki bivamo v ravnini. Življenje v alpskem svetu je že od nekdaj pomenilo tudi iznajdljivost, prilagodljivost in upornost razmeram, ki vladajo v strmem, vzpetem svetu, na višjih nadmorskih višinah in v ostrejših vremenskih pogojih. Skozi stoletja se je oblikovala alpska kultura, ki pogosto preide v mitologijo, v bistvu pa predstavlja način življenja $v$ Alpah. Le kdo ne pozna zgodbe o drznem fantiču Kekcu, ki s svojo upornostjo, vztrajnostjo in bistrostjo premaga vsako težavo. Skozi mitologijo se je oblikovala tudi alpska identiteta, ki jo danes v različnih delih Alp vsaka država dojema po svoje in jo bolj ali manj uspešno tudi ohranja.

\section{PROBLEMI V ALPAH}

Alpski svet je v obdobju gospodarskega razcveta Evrope naletel na krizo v več pomenih. Težave so nastopile najprej s povečano mobilnostjo prebivalstva in dinamiko družbenih procesov, na kar tradicionalno zaprte sredine $\mathrm{v}$ alpskem svetu niso bile pripravljene. To se je pokazalo z izgubo identitete $\mathrm{v}$ krajih, ki so doživeli turistični razcvet na eni strani, medtem ko so kraji, ki so še naprej ostajali zaprti in vse bolj preiferni, začeli doživljati demografsko krizo, ki se je odražala s staranjem prebivalstva in kasneje depopulacijo. Družbeni procesi v Alpah danes koncentrirajo poselitev turističnih regijah, v dolinah ter kotlinah, hkrati pa številna hribovita območja ostajajo brez prebivalcev.

Razgradnja tradicionlane alpske družbe morda niti ni največji problem Alp. Vse večji posegi človeka v delovanje ne samo lokalnih, pač pa tudi planetarnih krogotokov, so v mnogih okoljih začeli prinašati vse bolj občutne spremembe. Pri teh procesih imajo Alpe za Evropo, pa tudi širše velik pomen, saj so alpski ekosistemi zaradi ekstremnih naravnih pogojev zelo občutljivi in krhki, ter zato indikator sprememb v okolju.

Problemi razvoja in varovanja alpskega sveta so kmalu opozorili tudi širšo okolico, saj so Alpe tudi območje obnavljajna naravnih virov, npr. največji vodnjak Evrope. Območje Alp je danes območje najbolj razvitih svetovnih držav. Tri alpske države v skupini G7, poleg tega pa so na območju Alp še Avstrija, Švica in Liechtenstein, ki sodijo med bogatejše države v Evropi. Določena izjema je Slovenija, ki pa na številnih področjih sledi omenjenim državam. Interesi kapitala so zelo kmalu trčili v interese okolja.

\section{DOGOVORI O VAROVANJU ALPSKEGA SVETA}

Alpske države so se teh problemov dokaj kmalu zavedle in rezultat tega so mednarodni dogovori in konvencije, ki urejajo razvoj dejavnosti in rabo okoljskih sestavin na območju Alp. Tako danes v alpskem prostoru poznamo Alpsko konvencijo, Bernsko konvencijo (Konvencija o ohranjanju Evropskih naravnih življenjskih združb in naravnega življenjskega 
prostora), pomembna je tudi Ramsarska konvencija (Konvencija o mokriščih, ki imajo mednarodni pomen, zlasti kot prebivališča močvirskih ptic). Konvencijo o varstvu AlpAlpsko konvencijo so podpisale vse alpske države, v veljavo pa je že stopila v Nemčiji, Avstriji, Liechtensteinu in Sloveniji.

Izmed naštetih držav je pri uresničevanju Alpske konvencije največ naredila Avstrija, ki poleg številnih aplikativnih ukrepov na lokalni ravni (npr. turizem brez avtomobila v občini Werfenweng, ureditev biosfernega rezervata Grosses Walsertal itd.) tudi na zakonodajni ravni dnevno zaposluje pravne strokovnjake, ki ugotavljajo, kako določila Alpske konvencije skladno in čim manj boleče vpeljati v aktivnosti v prostoru.

Karta 1: Območje veljavnosti Alpske konvencije v Sloveniji s pripadajočimi višinskimi pasovi. Map 1: Area where Alpine convention is valid in Slovenia.

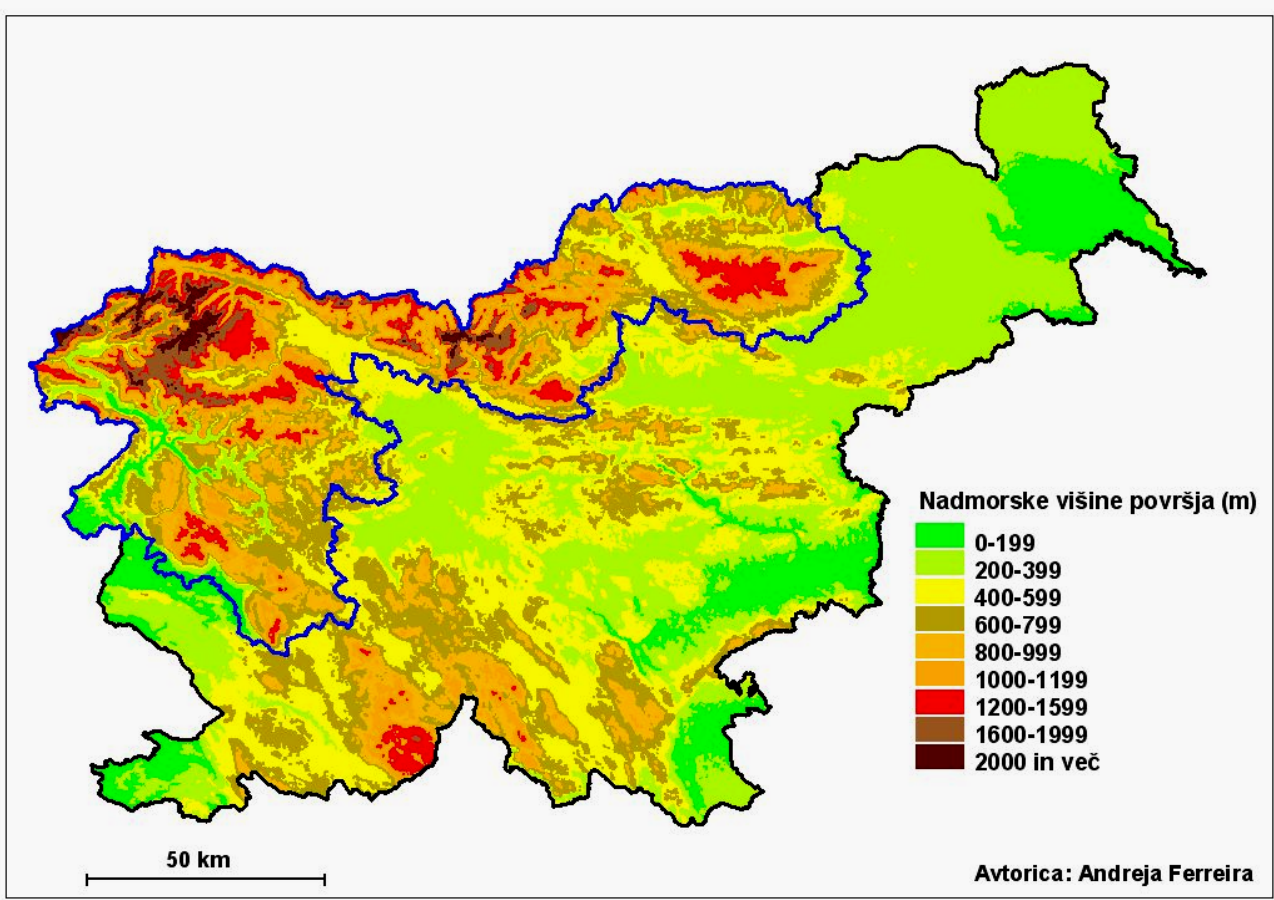

Dojemanje alpskega prostora in njegovo upravljanje je v vsaki državi drugačno. Podobno je tudi obravnavanje sicer skupnih dokumentov - kot je Alpska konvencija. Slovenija je v začetnem obdobju uveljavljanja Alpske konvencije prevzela pomembno vlogo in je z aktivnim sodelovanjem sredi devetdesetih let prejšnjega stoletja pozitivno presenetila ostale udeleženke. Alpski konferenci je predsedovala v letih 1995 - 1998, v tem času pa sta bili v Sloveniji dve Alpski konferenci, na Brdu leta 1996 in na Bledu dve leti pozneje. Morda tudi zato, ker je mladi državi tedaj primanjkovalo mednarodnih povezav in ji je udeležba $\mathrm{V}$ ugledni družbi alpskih držav pomenila svojstveno promocijo. Kasneje je bila vnema Slovenije na poti k sprejemanju Alpske konvencije precej manjša. Po nekajletnem mrku - je 
konec novembra 2003 Slovenija vendarle podpisala in ratificiarala tudi izvedbene protokole Alpske konvencije, aprila 2004 pa je Alpska konvencija stopila v veljavo tudi v Sloveniji.

Kljub vznesenosti Ministrstva za okolje, prostor (in tedaj še energijo) ob podpisu Alpske konvencije, pa se prava pot njenega uresničevanja šele začenja. Konvencija z osmimi izvedbenimi protokoli (več o njih na www.alpenkonvention.org) bo dejansko v ponos Sloveniji šele tedaj, ko jo bomo izvajali na lokalni ravni. Stališče predstavnikov države, ki so sodelovali pri vpeljevanju Alpske konvencije v slovenski pravni red je, da so določila , ki jih konvencija vsebuje že sprejeta $v$ sektorskih zakonih (Zakon o gozdovih, Zakon o varstvu okolja, Zakon o ohranjanju narave itn.), čemur ne gre oporekati. Postavlja pa se vprašanje izvjanja te zakonodaje, kajti potemtakem, če pogrešamo izvajanje Alpske konvencije, potem pogrešamo izvajanje zakonodaje.

\section{CIPRA}

Nastajanje Alpske konvencije je ves čas budno spremljala in nanj vplivala tudi Mednarodna komisija za varstvo Alp-CIPRA International (v nadaljevanju CIPRA). Poznavalci večkrat pravijo, da je Alpska konvencija celo otrok CIPRE. Čeprav se Alpska konvencija sprejema na mednarodni ravni, kjer sodelujejo pristojni resorji alpskih držav, pa kot opazovalka ves čas sodeluje tudi CIPRA, kar nedvomno potrjuje vlogo CIPRE kot nekakšnega »idejnega « vodje pri Alpski konvenciji. Nevladna organizacija CIPRA ima v vseh alpskih državah nacionalne odbore, ki delujejo v skladu s skupnimi načeli CIPRE. Te lahko strnemo kot prizadevanja za trajnostni razvoj alpskega prostora in ohranitev alpske kulutrne pokrajine $\mathrm{z}$ njeno naravno in kulturno dediščino.

CIPRA Slovenija, društvo za varstvo Alp, je slovenski člen CIPRE. Slovenija je sodelovala pri CIPRI že v času nekdanje Jugoslavije, kot nevladna organizacija, pa deluje CIPRA Slovenija od leta 2000.

Kot nevladna organizacija (NVO) deluje na področju trjnostnega razvoja slovenskega alpskega prostora in njegovega varovanja. Vzvodi delovanja CIPRE Slovenija kot NVO so predvsem osveščanje strokovne in laične javnosti o procesih in posegih $\mathrm{v}$ alpskem prostoru ter promocija trajnostnega načina življenja. Po svojih zmožnostih se CIPRA Slovenija loteva tudi aplikativnih in raziskovalnih projektov.

\section{TEŽIŠČE DELOVANJA}

Danes deluje CIPRA Slovenija na okoljskih temah, katerim je državna politika v preteklosti namenila premalo pozornosti, ali pa so bile narejene določene napake in $\mathrm{s}$ tem negativni učinki.

Trajnostna prometna politika je gotovo eno tistih področij, ki jim Slovenija do sedaj ni namenila dovolj pozornosti. Ne meneč se za probleme in ukrepe Avstrije in Švice, se je slovenska prometna politika začela in končala pri gradnji avtocest in obnovi obstoječih cest.

Kam se bodo preusmerili prometni koridorji, ki morajo plačevati vedno večjo ceno $\mathrm{v}$ notranjih alpskih prelazih? Ali je Slovenija pripravljena kapacitete oprtnih vlakov dvigniti 
na ustrezno raven, da tovornjaki ne bodo zapustili kompozicij v Beljaku, pač pa v Dobovi? Ali poznamo eksterne stroške prometa, ki jih povzroča v tovorni tranzitni promet?

Prometno obremenjevanje je danes največji okoljski problem v Alpah. V Sloveniji v devetdesetih letih prejšnjega stoletja teh problemov zaradi znanih dogodkov na Balkanu ni bilo čutiti $\mathrm{v}$ toliki meri. A razmere so se spremenile in tranzitni tovorni, kot tudi tokovi osebnih vozil na jugovzhod so ponovno oživeli, medtem ko se koridor Barcelona - Kijev krepi ves čas. Razvoj Slovenije kot turistične destinacije, ki je prednosten cilj slovenske turistične politike, tudi prinaša vse več prometa, na katerega marsikje niso pripravljeni.

Celostna prometna politika mora biti na te trende pripravljena in to na vseh sektorjih prometa. Na to jo opozarja tudi vse več lokalnih civilnih združenj, ki opozarjajo na nevzdržne prometne razmere ali na neskladno prometno politiko na različnih predelih Slovenije (Prekmurje - Dolga vas, Trebnje, Ljubljana Šentvid, Domžale ipd.). Na ta način so se pred desetletjem ali dvema rojevala civilna združenja tudi v drugih alpskih državah in opozarjala na napake državne politike. Mar moramo v Sloveniji ponavljati iste napake?

Tudi na področju zavarovanih območij je slovenska politika zaspala. Projekt ustanavljanja zavarovanih območij, pod sloganom »Parki za življenje« je klavrno propadel sredi devetdesetih let. Na cerkniškem je občina Cerknica zaradi nezaiteresiranosti države pri ustanavljanju regijskega parka Snežnik, leta 2002 samostojno razglasila Notranjski regijski park (medmrežje 1), ki je zaživel tudi med lokalnim prebivalstvom.

Edino zavarovano območje, ki je bilo ustanovljeno s strani države v devetdesetih letih je bil Krajinski park Goričko, resnici na ljubo pa se je to zgodilo zlasti zaradi pritiska evropske politike, ki je zagotovila velik del sredstev in bi jih država v primeru neustanovitve parka morala vrniti. Na žalost se ta park še ni vživel v zavest lokalnega prebivalstva.

CIPRA Slovenija je že pred nekaj leti oživila staro idejo po ustanovitvi Kamniškosavinjskega regijskega parka. Izdelana je bila tudi analiza obstoječih zavarovanih območij na območju Kamniško-Savinjskih Alp, kjer smo pokazali, da ustanovitev regijskega parka z jedrom v Logarski dolini, ki je že zavarovano območje, ne bi bistveno spremenilo obstoječega režima. S smotrnim upravljanjem in promocijo parka pa bi območje dobilo pomemben razvojni impulz.

Nespretna politika države do zavarovanih območij se je pokazala tudi pri nastajanju novega zakona o Triglavskem narodnem parku. Obstoječi zakon, ki je iz leta 1983, ni več ustrezna podlaga edinemu slovenskemu narodnemu parku. Vlada je po polžje pripravljala novi zakon, prehitela pa jo je skupina poslancev, ki je pripravila svoj predlog zakona, katerega je stroka ocenila kot popolnoma neprimernega za narodni park. Civilna družba na čelu s koalicijo nevladnih organizacij, kjer je aktivna tudi CIPRA Slovenija, je uspela ustaviti postopek sprejemanja tega zakona in pripravila nov predlog, ki ga je predložila vladi Republike Slovenije.

\section{IZZIVI OSTAJAJO}

Izzivov pri varovanju alpskega sveta in njegovem trajnostnem razvoju v Sloveniji je še veliko več. Potrebno bo zagotoviti ugodne pogoje za ohranitev poselitve v hribovitih predelih in s tem ohranitev tradicionalne kulturne pokrajine. Ohraniti je potrebno vsaj nekaj pašnih 
planin, točno določiti prednostne dejavnosti, ki naj bodo gonilo razvoja v občutljivem alpskem svetu, določiti območja miru, območja intenzivnejšega turističnega razvoja in še bi lahko naštevali.

Pri teh odločitvah bosta morala biti udeležena tako lokalno prebivalstvo kot civilna družba. Ocenjujemo, da bo vloga nevladnih organizacij in civilne družbe nasploh vse pomembnejša, saj se postopno spreminja tudi odnos politike do civilne družbe, kar se je pokazalo tudi pri kritiki predloga poslancev o zakonu o TNP. Slovenija je podpisnica Aarhuške konvencije (Konvencija o dostopu do informacij, udeležbi javnosti pri odločanju in dostopu do pravnega varstva pri okoljskih zadevah), česar se javnost vse bolj zaveda, $\mathrm{s}$ tem pa narašča vloga civilne družbe. Vse več je tudi nevladnih organizacij, ki svoje delovanje prednostno ali vsaj deloma namenjanjo problemom alpskega sveta (CIPRA Slovenija, Mountain Wilderness Slovenije, Slovensko ekološko gibanje, Društvo za naravo Jalovec itd.). Primer nastajanja in sprejemanja Alpske konvencije nam kaže, kako pomembna je lahko vloga nevladnih organizacij in civilne družbe pri varovanju okolja.

Tako stroka, politika, kot tudi civilna družba pa si morajo prizadevati, da bodo odločitve in ukrepi $\mathrm{v}$ alpskih pokrajinah $\mathrm{v}$ resnici naravnani trajnostno ter da bodo izkoristili potenciale slovenskega alpskega sveta in z njimi še dodatno obogatili ta prostor.

\section{Vir}

Medmrežje 1: http://www.notranjski-park.si/odlok_usatnovitev.pdf, citirano 6.5. 2005

\section{ALPINE POLICY AND NON-GOVERNMENTAL ORGANISATIONS}

\section{Summary}

Alpine space has always been a space of different way of life. Different natural conditions resulted in tougher conditions for activities such as farming or cattle breeding. Living in the mountainous landscape through centuries developed its own way of life, its culture and also its identity.

After huge economic development, which Alpine countries have faced in the last 50 years, the Alpine space faces two main problems.

Demographical problems, which are reflected in depopulation of some regions and a strong seasonal concentration in others.

Ecological problems, which are reflected in degradation of some areas where industry, transport or tourism are concentrated.

As an answer to increasing impacts of progress in vulnerable alpine ecosystems, a part of society started to take action to protect the Alps. The movement for the protection of the Alps organized in many societies, institutions and finally also at a political level, started to achieve results. (Some) Alpine countries have signed documents (for example, Bern convention, Alpine convention, Ramsar convention) which are very important for the protection of nature and the environment in the Alps. 
Alpine convention (www.alpineconvention.org) is a document, which is unique for the Alpine space. It was signed by all Alpine countries. However, until now it has been become part of legislation only in Liechtenstein, Germany, Austria and Slovenia.

The main participant in the formation of Alpine convention was CIPRA International, an International commission for the protection of the Alps. As a NGO, CIPRA International has been the leader of the idea about the Alpine convention for decades.

As a part of CIPRA International, CIPRA Slovenia works in the field of sustainable development and protection of the Alpine space in Slovenia. Today, CIPRA Slovenia as a NGO works in the field of education and implementation of some environmental projects, such as establishment of the Kamniško-Savinjski regional park. CIPRA Slovenia is also active in a coalition of NGOs in the formation of a new proposal of the law about the Triglav national park and in efforts for sustainable transport policy in Slovenia.

However, issues of social and environmental problems in the Alps demand more than just activities of NGOs such as CIPRA Slovenia or some others. To solve these tasks, an integral approach from all parts of society (policy, institutions, civil society and locals) is necessary. 